\title{
Moving Seaweed Farms from Shallow to Deep Seawater to Cope with Warming and Diseases in Zanzibar. Current Socio-Economic and Cultural Barriers
}

\author{
Makame Omar Makame ${ }^{1,3}$, Ali Rashid Hamad ${ }^{2,3}$, Muhammad Suleiman Said ${ }^{4}$, Alice Mushi ${ }^{2} \&$ Khadija Sharif $^{2}$ \\ ${ }^{1}$ The State University of Zanzibar (SUZA), Tanzania \\ ${ }^{2}$ Milele Zanzibar Foundation (MZF), Tanzania \\ ${ }^{3}$ Ministry of Blue Economy and Fisheries Zanzibar (MBEF-Z), Tanzania \\ ${ }^{4}$ The Panje Project (TPP), Tanzania \\ Correspondence: Makame Omar Makame, The State University of Zanzibar (SUZA), Tanzania. E-mail: \\ makame.makame@suza.ac.tz
}

Received: June 21, 2021

doi:10.5539/jsd.v14n5p29
Accepted: July 30, $2021 \quad$ Online Published: August 15, 2021

URL: https://doi.org/10.5539/jsd.v14n5p29

\begin{abstract}
This study aimed at identifying the climate and non-climate stressors affecting the seaweed farming practices. It also examines the deep water seaweed farming as a viable adaptation measure to these stressors and barriers that could constrained female seaweed farmers who are the majority. The study was carried out in six selected groups, two groups were from South District, Unguja Main Island (Furahiya Wanawake-Paje and Flower GroupMuungoni). And four groups were selected from Pemba Island (Tuwe Imara and Umoja Kazi- East Msuka and Ipo sababu and Umoja ni Nguvu - East Tumbe) from Micheweni District. These groups were selected because they participated in previous project implemented by Milele Zanzibar Foundation (MZF) and The Panje Project (TPP). Questionnaire interview collected various information related to the study from 111 seaweed farmers who are members of these groups. Information such as baseline seaweed production, climate change and diseases that affect seaweed production, farmer's awareness on moving seaweed farms to deep water to cope with increasing warming and diseases and their capacity to swim as prerequisite for the adoption of this coping strategy. The focal group discussions were conducted in all six groups to collect various information to triangulate the findings collected from the questionnaire interview. The data obtained from three methods analyzed using descriptive statistics. The findings show that seaweed farming production has declined at least over the last seven years. Climate change and its variability, diseases, over utilization of shallow water space for farming seaweed, COVID 19 and price has contributed a lot in the observed decline. Deep water ( 0.5 meter during low tide and 3-5 meters during high tide) seaweed farming seen as viable option to cope and adapt to increasing warming and diseases but its adoption especially amongst female seaweed farmers constrained by their limited capacity to swim and their limited ownership of the vessels. The study also identified other barriers such as age, gender and cultural factors that could constrained female seaweed farmers from participation in swimming and sea safety training. To facilitate adoption of the deep-water seaweed farming method amongst the seaweed farmers, concerted effort should be made to overcome the barriers that are likely to limit the massive adoption of this method.
\end{abstract}

Keywords: adaptation, seaweed farming, deeper seawater seaweed farming and climate change

\section{Introduction}

Across the site's seaweed farmers used traditional method for seaweed farming in which nylon ropes with seaweed branches tied to them are fixed between wooden pegs, and arranged in lines of approximately 50 lines per block. These allows for growth under water in the intertidal zones for six weeks before harvest (Richmond, 2010; Msuya, 2011). According to Makame (2013) the duration between planting and harvest may be shorter, depending on the season. During winter (June-August), the cooler seawater allows for faster growth compared with other seasons. Summer (December-February) normally associated with low growth, as temperature is too hot for the seaweed to grow. This make seaweed vulnerable to increasing warming condition both attributed to sea surface temperature and atmospheric temperature. Studies conducted in the coastal Zanzibar suggested that majority of the seaweed farmers are female, however, the number of male farmers is rising especially in Pemba Island due to unreliability 
of other sectors (Makame, 2013; Wallevik and Jiddawi, 1999). Culturally, men are obliged to cover all household expenditure (Eklund and Petterson, 1992), nevertheless, income earned by women also used to cover household expenses (Wallevik and Jiddawi, 1999).

Seaweed farming is an economic activity actively pursued for over 30 years in Zanzibar where two red seaweed species namely Eucheuma denticulatum commercially known as spinosum and Kappaphycus alvarezii commercially known as cottonii are farmed (Hassan and Othman, 2019; Msuya, 2012; Msuya and Hurtado, 2017). As the third largest source of income for the islands, over the years, seaweed has grown in importance as a source of livelihood for men and women in Zanzibar (Makame, 2013; Msuya and Hurtado, 2017). Zanzibar was and continues to be the third largest producer of red seaweed globally after Indonesia and the Philippines, for example in Zanzibar produced 15,000 tons in 2012, the highest ever produced (Department of Marine Resources, Zanzibar 2012). Seaweed production has decreased from 15,000 t (dry weight) in 2012 to a stagnant 11,000 t between 2016 and 2018 (Figure 4) with a sharp increase in 2015, which was most probably due to problems of production in South East Asia (SEA). This caused a sharp increase in prices that attracted more farmers or increased farmers' enthusiasm, since a lack of supply (production) in SEA caused buyers to buy more from Tanzania (Msuya, 2020). Apart from diseases, the decline also linked with exposure to increasing warming condition, associated with increasing atmospheric and sea surface temperatures where it grow (Makame, 2013; Ndobe et al., 2020) and drop in the price of the seaweed which forced part of the farmers to quit seaweed farming (Makame 2013; Msuya, 2012). For example, Msuya (2012) found a positive relationship between the decrease in the production of seaweed and decreasing the number of farmers in Zanzibar. The drop in production has gone hand in hand with a drop in global prices, both of which have had a devastating effect on the lives of the local seaweed farmers whose lives depend on this crop for survival (Msuya et al., 2007). This drop in global prices attributed to subsidization of the crop in countries competing to win over the global seaweed market. National efforts to develop a comprehensive seaweed framework and policy to ensure Zanzibar can continue to compete in the global seaweed market while simultaneously protecting the livelihoods of the smallholder seaweed farmers is crucial.

The common seaweed farming method used by the majority of the farmer is off-bottom method (Msuya, et al., 2007). This method conducted in the intertidal areas where farmed seaweed left in shallow water depth of less than 10 centimeters during low tides and thus exposed to sunlight and warming condition. This make seaweed vulnerable to the increasing warming attributable to climate change and local variability. Increase the incidence of ice-ice disease and epiphyte infestation also associated with increasing warming conditions. As climate keep on changing globally, existing situation highlight the need for adaptation to build societal resilience against the impact of climate change. According to IPCC (2014) in its fifth assessment report show that each of the last three decades has been successively warmer than any preceding decade since 1850. Studies in Zanzibar and Tanzania also revealed that variability in temperature and rainfall is already reality and cause unprecedented impact livelihood activities (Makame, 2013; TMA, 2019). For example, a study by Makame (2013) found increasing warming in minimum temperature increasing variability in the rainfall received and abnormality in the seasons both related to temperature and those related rainfall over the last two decades. While TMA (2019) has revealed that, annual mean temperature for 2019 was $0.8 \mathrm{C}$ warmer than long-term average (1981-2010). This made 2019 the fourth warmest year after 2003, 2010 and 2005 (TMA, 2019). The response to disease infestation of the seaweed crops, known to be effects of climate change, requires innovative and mitigation efforts that will help local seaweed farmers, especially women, to become resilient against these changes. Seaweed farming in Zanzibar is an economic activity predominantly, about $80 \%$, run and operated by women, especially at the production level. While some men have been engaged, especially higher in the value chain, as intermediaries and buyers, women are more commonly engaged in planting, harvesting, handling and selling the crop. The current effects of disease infestation of the most sensitive and less resistant species of Kappaphycus alvarezii species means that women are now forced to plant and harvest the seaweed in deep waters. Deep-water seaweed farming method considered as a noble adaptation option to cope within increasing seaweed diseases and warming at the shallow where it currently farmed using off-bottom methods. This is because deep seawater will reduce exposure of the seaweed to the sun light, warming condition and diseases. A study by Msuya et al., (2007) compared the traditional method (off-bottom) and new deep water floating line and found that the latter method is more economically superior, high productivity and significant reduction of seaweed die-offs. Despite the superiority of the deep-sea water floating method compared with off-bottom still the adoption of the deep seawater floating lines to cope with diseases and warming still minimum amongst the farmers. The penetration of this new method within social system probably constrained by various factors. However, it is obvious the deep-water floating lines method brings a new challenge of drowning and sea safety into the sector, which makes women particularly vulnerable. According to the WHO, drowning is one of the leading causes of preventable deaths globally. Although a silent killer and data is insufficient in most developing countries, recent studies have shown that drowning is a major health burden in Africa with the most 
vulnerable groups being children under 5 and fisher folks in coastal communities. A recent study conducted commissioned by the Royal National Lifeboat Institute (RNLI) and The Panje Project assessing the perceived drowning risks in Zanzibar found that fishermen and female seaweed farmers are among the groups most vulnerable to drowning. The data generated from this study found that only $13 \%$ of the women interviewed were able to swim (Drowning risk assessment - Zanzibar Island Study Report, 2018). Knowledge of safety around water and how to rescue someone when drowning was also generally low among those interviewed.

With increasing warming due to climate change and its variability, vulnerability of the seaweed farmers have increased tenfold now that seaweed farming must be done in deep waters. This triple burden of falling global prices, increased higher risk of drowning and climate change poses a significant threat to the livelihoods of the seaweed farmers, especially the women. Both gender dynamics and implications of these drastic changes exert more pressure to seaweed farmers especially women. To increase adaptation and thus building local resilience, these risks must be addressed and the barriers to adaptation must be overcome. This article therefore, examine the adoption of deep seawater floating lines as adaptation strategy to increasing warming condition and diseases. It also examine the barriers that currently constrained the uptake of this option to adapt with changes.

\subsection{Thinking about Barriers to Adaptation}

As current and future climate change are inevitable, humanities should strive to develop adaptation capacity to be able to mitigate these impacts and thus sustain their existence aboard. However, it is now widely acknowledged that the adaptation options are not always diffused and adopted within the social systems as desired (Regmi and Bhandari, 2013; Islam et al., 2014; Shackleton et al., 2015; Masud et al., 2017). This delayed is associated with barriers, which constrained farmers or society from achieving the adaptation goal (Islam et al., 2014; Shackleton et al., 2015; Masud et al., 2017; Pandey et al., 2018). Barriers are defined as obstacles that can be muted/overcome (Moser and Ekstrom, 2010). This is contrary to limit which associated with obstacle that are in some sense absolute (Moser and Ekstrom, 2010; Adger et al., 2007; Adger et al., 2009). Studies have identified a wide range of barriers from social and cultural barriers to economic barriers that constrained communities from adapting to the impact of climate change (Moser and Ekstrom, 2010; Adger et al., 2007; Adger et al., 2009; Masud et al., 2017; Makame, 2013; Islam et al., 2014). For example, a study by Islam et al., (2014) found a wide array of barriers that constrained fishermen in Bangladesh to cope and adapt to climate change. These include poor boats, inaccurate weather forecast, poor radio signal, lack of access to credit, low incomes, underestimation of cyclone occurrence, lack of education, skills and livelihood alternatives, unfavorable credit schemes, lack of enforcement of fishing regulations and maritime laws, and lack of access to fish markets (Islam et al., 2014). In Malaysia, barriers such as age, education level, farm income, farm experience, limited access to agricultural extension, lack of credit facilities and limited access to agricultural markets constrained farmers from adaptation (Masud et al., 2017).

As noted earlier barriers for greater extent, hold back the decision of an individual or society to adopt adaptation strategy and thus adapt the inevitable impact of climate change. However, with concerted effort these barriers can be overcome and allow mass adoption of the adaptation options within social system and thus building local resilience against the climate change impacts. For example, Adger et al., (2009) argue that, barriers especially social ones are in fact soft barriers; they can be overcome with sufficient political will, social support, resources, and effort. Similarly, while studying barriers to adaptation in Nepal Regmi and Bhandari, (2013) argue that building adaptation strategies on the existing knowledge and skills and redefining roles and responsibilities of the institutions would facilitate adaptation and overcome barriers.

\section{Study Areas}

This study conducted in both Pemba and Unguja, which collectively formed Zanzibar islands. For the purpose of this study, six seaweed groups were purposely selected. Their selection was based on their participation in the previous project financed by Milele Zanzibar Foundation, an organization which participate in the implementation of this research and innovation project is also financed this research. Within these six selected groups, two groups were from South District of Unguja which is the main Island of Zanzibar these groups were Furahiya WanawakePaje and Flower Group-Muungoni (Figure 2a and 2b). And four groups selected from Pemba Island were Tuwe Imara and Umoja Kazi- East Msuka and Ipo Sababu and Umoja ni Nguvu-Tumbe) from Micheweni District (Figure 1a and 1b).

In all these two districts under study, livelihood strategies such as farming, fisheries and seaweed farming are the main stay of the households. Apart from these strategies, in Paje tourism is also a very important livelihood activity although studies show that very few villagers across the islands who are directly employed in the sector. Seaweed farmers in Paje like any other tourism villages in Zanzibar are facing conflicts with tourism related activities as they share the same intertidal zones. Both Districts are purely rural which characterised by higher illiteracy level 
(23.9\%) compared with urban which is $7.7 \%$. Female who are largely involved in seaweed characterised by higher illiteracy rate of $20.6 \%$ compared with $11.7 \%$ of men (SMZ, 2016). The 2014/15 household budget survey also show that Micheweni district ranked last in Pemba Island with $60 \%$ of the household with basic needs poverty while south district of Unguja ranked last with $26.3 \%$ of the household with basic needs poverty (SMZ, 2016). This is to say the shehia in which these groups are available are vulnerable to climate change and other linked stressors due to existing challenges such as poverty, illiteracy and over dependency of sensitive activities such as seaweed farming, agriculture and fisheries.

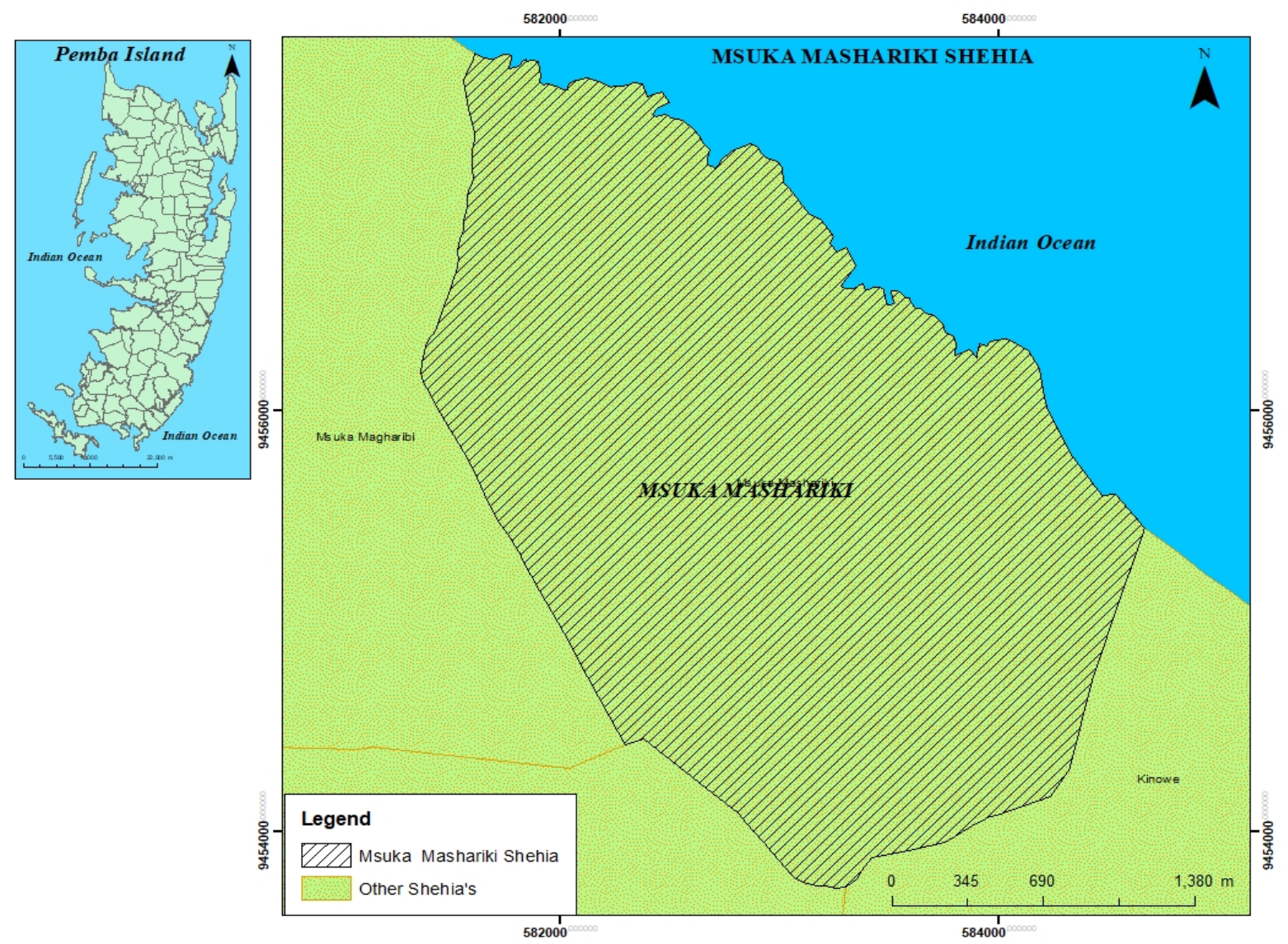

Figure 1a. Msuka Mashariki in Pemba Island, Zanzibar 


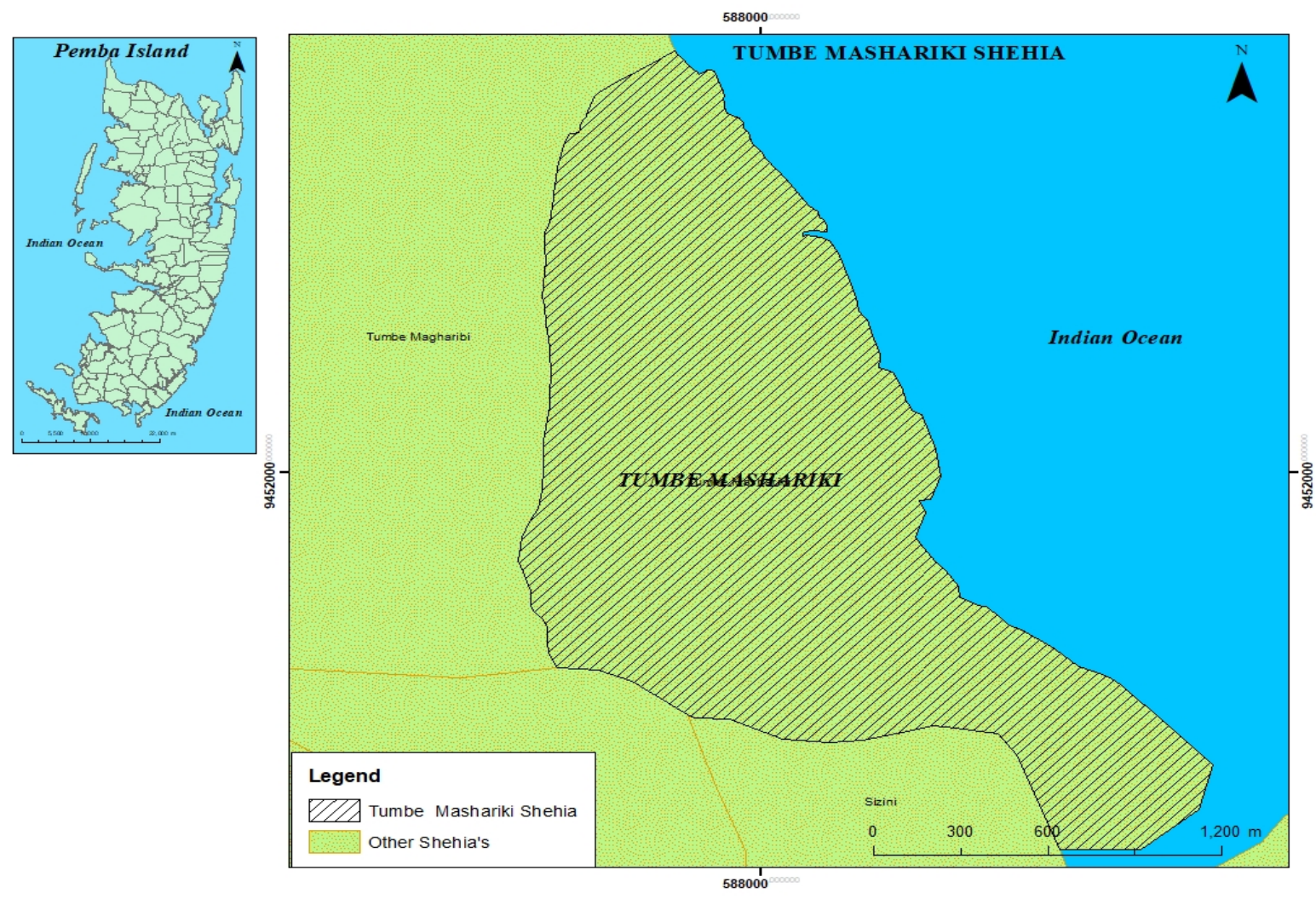

Figure 1b. Tumbe Mashariki in Pemba Island, Zanzibar

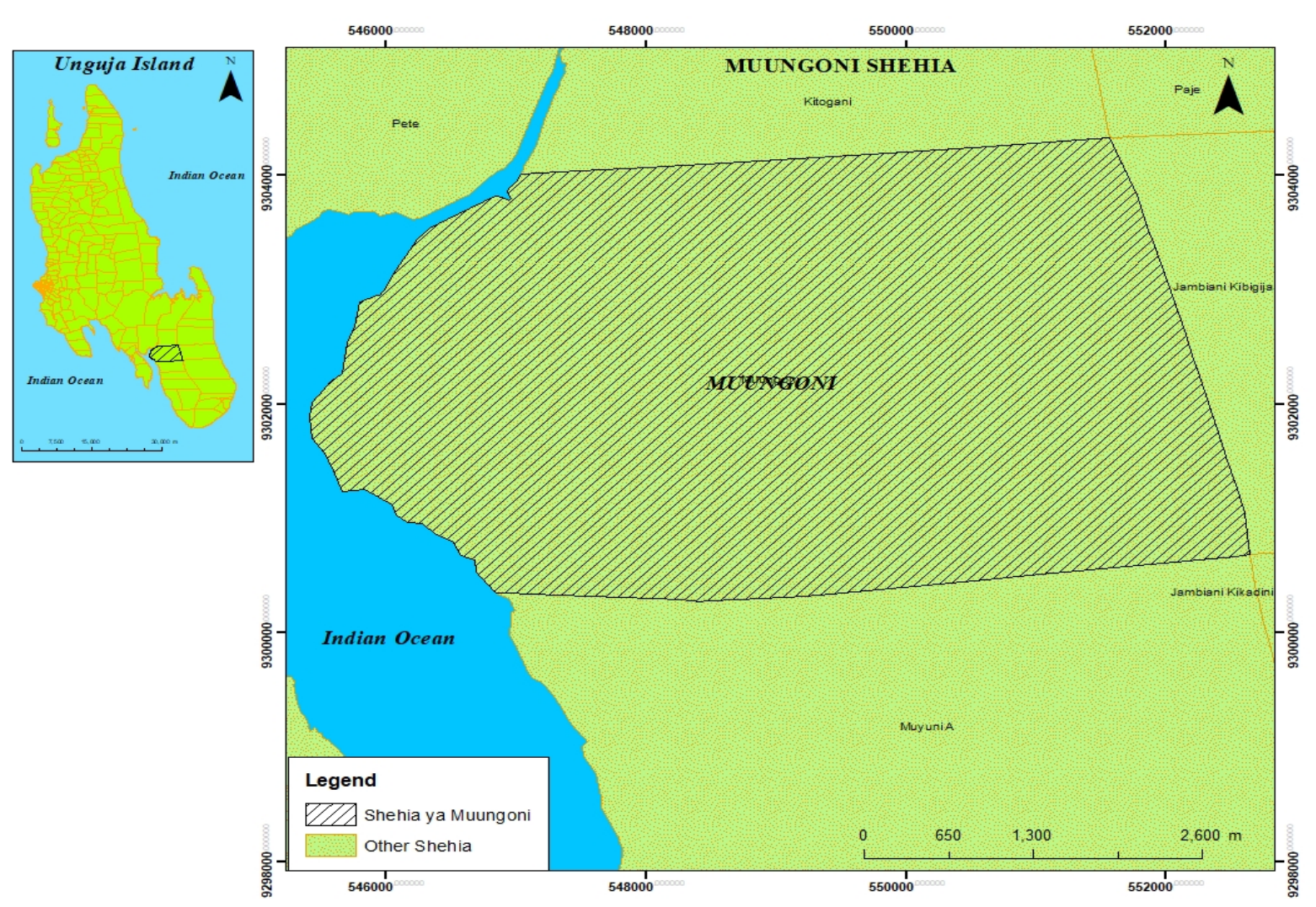

Figure 2a. Mungoni Shehia in Unguja Island, Zanzibar 


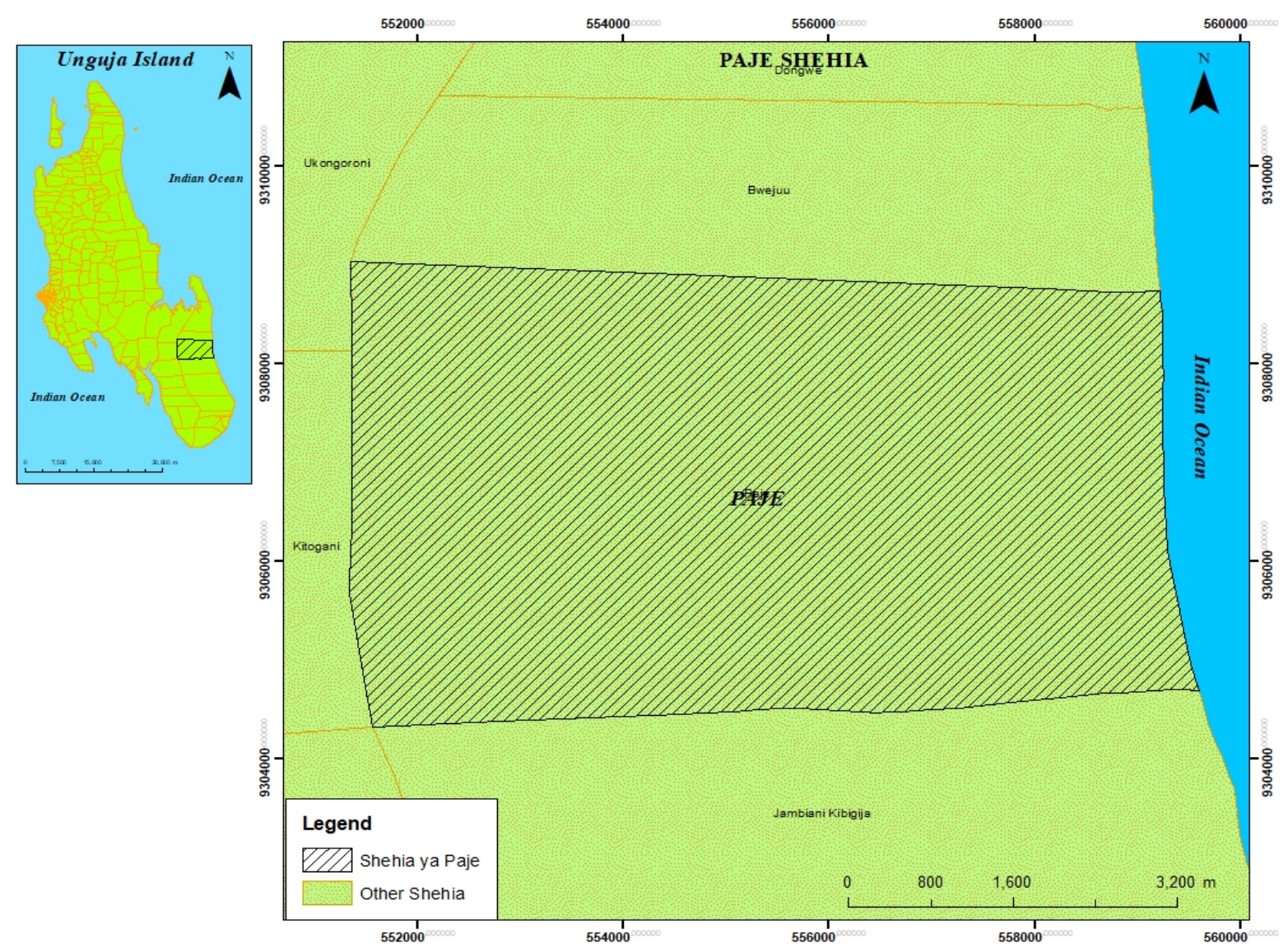

Figure 2b. Paje Shehia in Unguja Island, Zanzibar

\section{Methods}

This paper is a result of the yearlong research project aim at creating knowledge around building various capacities of seaweed farmers on producing and handling quality seaweed in deeper seawater to increase livelihood opportunities and strengthening resilience. All 111 members of the selected six groups across the sites were purposely selected for the study. Within this, 93 were female and 18 were male. Large number of female in these groups is due to the fact that seaweed farming is largely performed by female than men. Various methods were used to collecting data, these include questionnaire and group discussions. Questionnaire interview collected baseline information related to the population profile, seaweed production, climate change and diseases that affect seaweed production, social capital and saving, farmer's awareness on moving seaweed farms to deeper water to cope with increasing warming and diseases and their capacity to swim as prerequisite for the adoption of this coping strategy. The tool sought to understand the barriers (social and cultural) that are likely to limit the adoption of this coping strategy (Learning how to swim) amongst seaweed farmers. Group discussions were conducted in all six groups to collect various information to triangulate the findings collected from the questionnaire interview. The data obtained from three methods analyzed using descriptive statistics using SPSS.

\section{Results and Discussion}

\subsection{Existing Situation of Seaweed Farming}

The study found that apart from the seaweed farm owned by the visited groups, individual members also owned their own seaweed farm. The results revealed that farmers owned between one to five seaweed farms/blocks individually. However, majority of the members of these groups owned two seaweed blocks. The study revealed that number of farms per farmers influenced by the availability of inputs (seaweed cuttings, ropes, pegs, intertidal space for farming and labour). Based on the discussion with the farmers, the study found that the income of the seaweed farmers increasing within increasing the number of seaweed farms. A study by Makame (2013) in both Pemba and Unguja also found direct relationship between the number of seaweed blocks and income. Furthermore, correlation analysis was performed to underscore the relationship between gender and the number of blocks and 
family size and number of blocks. The results found no relationship between the number of seaweed blocks owned and gender in one hand and between the number of seaweed blocks and family size on the other. This means that the number of blocks are not influenced by gender or family size despite the fact female farmers who are majority draw labour from their husband, children and relatives from some stages of the seaweed farming that is preactivities, planting process, harvesting and market. However, the study found that husband normally assist their wife during harvest, as the fresh harvested seaweed is normally heavy. Similarly many female farmers are unable to ride the dhow as results they asked assistance from their husband to transport the seaweed onshore. Furthermore, being a member of a group an individual farmer had opportunity to draw labour from the group.

As seen earlier, the main inputs for the seaweed farmers are tree pegs cut from forest, ropes and seaweed cuttings (seeds) for transplanting. Other input such as vessels to aid transportation of seaweed during harvesting is also important. The study found that there are various sources in which, inputs are obtained by the seaweed farmers. There are group of the farmers who obtained these input from company that are buying and exporting seaweed and those that are buying these input by themselves. There is also a group of seaweed farmers, who obtained these input from various sources such as friends and relatives. The study observed that seaweed farmers had to sell their seaweed to the same company that financed their inputs while those finance their inputs they have freedom on which company to sell their seaweed. With limited options for buyers and local processing industries, seaweed farmers whether they have financed their seaweed inputs themselves or financed by the companies all had to sell their seaweed to the seaweed companies. When asked who decide the price, and whether they are satisfied with the price. The results in Table 1 show that $90.8 \%$ of the seaweed farmers across the sites believed that the price they received for their seaweed decided by the buyers, and in Table $2,76.4 \%$ of the respondents are not satisfy with the price.

Table 1. Parts that are deciding the seaweed price

\begin{tabular}{ccc}
\hline Groups & The buyer & My self \\
\hline Furahiya Wanawake & $85.0 \%$ & $15.0 \%$ \\
Flower Group & $91.6 \%$ & $8.3 \%$ \\
Tuwe Imara & $84.2 \%$ & $15.8 \%$ \\
Ipo Sababu & $100.0 \%$ & $.0 \%$ \\
Umoja Kazi & $85.7 \%$ & $14.3 \%$ \\
Umoja ni Nguvu & $100.0 \%$ & $.0 \%$ \\
Total & $\mathbf{9 0 . 8 \%}$ & $\mathbf{9 . 2 \%}$ \\
\hline
\end{tabular}

Table 2. Satisfaction of the seaweed price

\begin{tabular}{cccc}
\hline Groups & Yes & No & Somehow \\
\hline Furahiya wanawake & $25.0 \%$ & $75.0 \%$ & $.0 \%$ \\
Flower Group & $27.3 \%$ & $63.6 \%$ & $9.1 \%$ \\
Tuwe imara & $22.2 \%$ & $77.8 \%$ & $.0 \%$ \\
Ipo Sababu & $30.0 \%$ & $70.0 \%$ & $.0 \%$ \\
Umoja kazi & $31.6 \%$ & $68.4 \%$ & $.0 \%$ \\
Umoja ni Nguvu & $.0 \%$ & $100.0 \%$ & $.0 \%$ \\
Total & $\mathbf{2 2 . 6 \%}$ & $\mathbf{7 6 . 4 \%}$ & $\mathbf{. 9 \%}$ \\
\hline
\end{tabular}

\subsection{Vulnerability of the Seaweed Farming to Climate Change and Other Existing Challenges}

The results of group discussion across the sites revealed that majority of the participants have perceived decrease in seaweed production. Those who perceived a decline in seaweed production normally give example of the past and present like I used to produce this much but now I produce very little compared with the previous years. In a survey seaweed farmers were asked to identify the reasons for the decrease. And the results in Figure 3 show that $48.1 \%$ and $39.5 \%$ believed that diseases and increasing warming conditions respectively are the reasons for the 
decrease. Diseases such as ice ice and epyphytes caused by the increasing warming conditions have been identified as major obstacle to the productiion of quality seaweed in Zanzibar (see for example Makame, 2013). The Majority of the farmers are currently farming using off-bottom method in shallow seawater areas where temperature and salinity viriability is very high causing phyisological stresses to farmed seaweed consequently leading to slow growth rate and low production. This necessitate the use of deeper water seaweed farming. Other reasons cited included sanility, increasing severity and frequency of wind stoms, lack of seaweed farming inputs and low price (Figure 3).

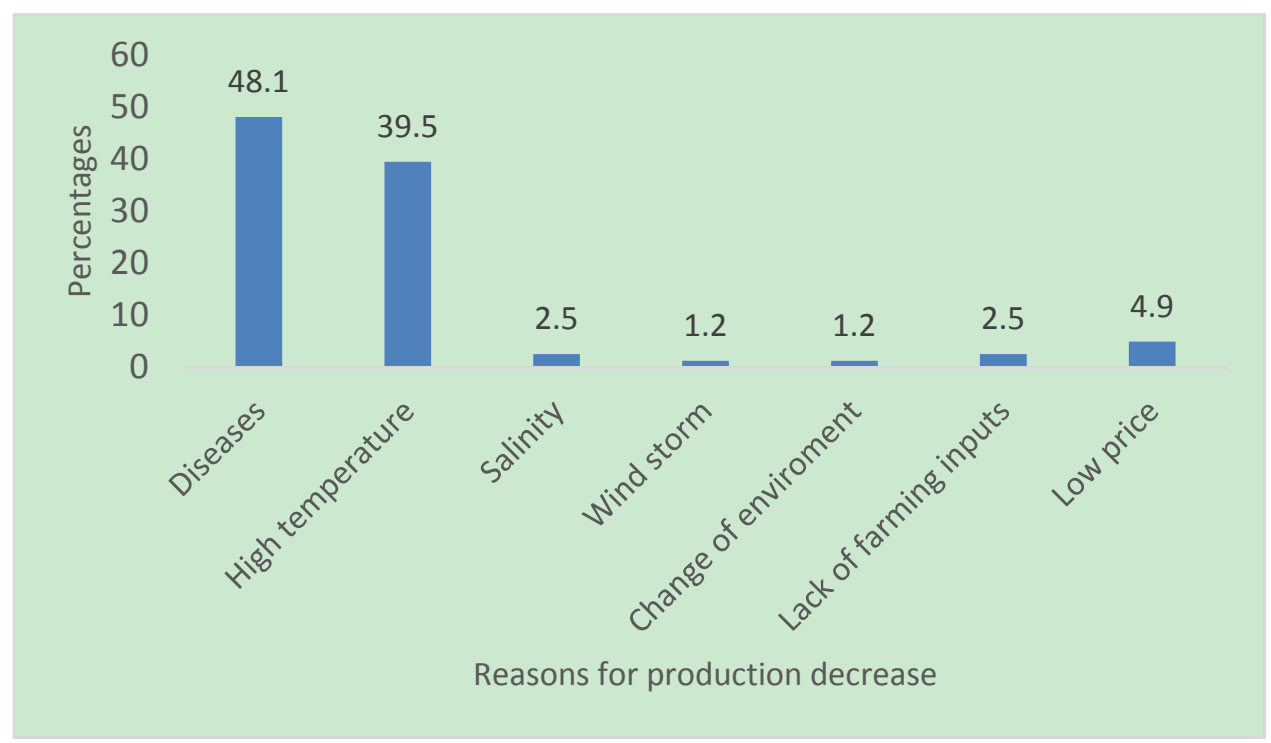

Figure 3. Reasons for Seaweed production decrease

With regard to small price obtained by the farmers, the study found a complexity of the whole transaction around the whole business of seaweed farming. Farmers believed that they put a lot of energy into the farming but they get minimum economic return compared to the effort they invested. However, the buyers argued that the price that they offer is the only option for them to remain afloat. Taxies surrounding the business and external competition with other global producers of the seaweed also made them remain with the price, which is perceived as exploitative by the farmers. The study found no or limited communication between seaweed farmers and seaweed associations created to help and assist the farmers in various issues including seaweed price. The results of group discussion observed limited understand of the existence of these association especially amongst female seaweed farmers who formed the bulk of seaweed farmers in Zanzibar. There are number of associations related to seaweed like Shehia seaweed committees (Formulated by the Department of Fisheries Development to connect seaweed farmers and the Government) and Association of Pemba Seaweed Farmers but farmers feel like that they are not part of these and they are not being helped by these associations. An interview with key informant from these associations revealed that these associations have not played a role of representing their grievances to Government and seaweed companies to raise the seaweed price and to tackle associated challenges facing seaweed farmers. Furthermore, even with this low price farmers are currently had no place to sell their seaweed, as a results majority of the farmers have large pile of dried seaweed in their homes. Companies that are normally buying are not regularly buying seaweed from the farmers. This has been attributable to the Covod-19 pandemic that affected the economy worldwide and thus reduced the demand for the seaweed as well. Buyers normally buy seaweed from the farmers when they receive order from the international buyers. This has affected the capacity of the women to save money and their participation to the saving groups.

The study also found that seaweed farming is located in the same areas where fishing and tourism activities also practiced. This situation has created competition of the places between these sectors. Seaweed attract herbivorous fish species, which feed from the weed and grasses. Fishermen are attracted by the increasing of these species in the seaweed farms and thus caused conflicts. Similarly, existence of the seaweed farmers in the tourism areas such as Paje perceived by the hotel owners as risk to their business. For them, seaweed farms, which contained ropes and pegs, are likely to affect water sports such as kite surfing as pegs and ropes could cause injuries to tourists. On the contrary, untreated water from hotels swimming pools and other uses had impact to seaweed farming. This water had nutrients that facilitate blooming of other organism such as sea urchins that can affect both seaweed and 
environment of tourism. As a result, seaweed farming become double exposed by both Covid 19 pandemic and climate change and local challenges that make this activities important to the women and households more vulnerable to poverty and food poverty. The results highlight the fact that seaweed farming is not only affected by diseases and increasing warming it also affected by number of challenges both external and internally. Figure 4 below highlight the decline of seaweed production since 2015. This decline could be attributed to various factors as discussed in this section.

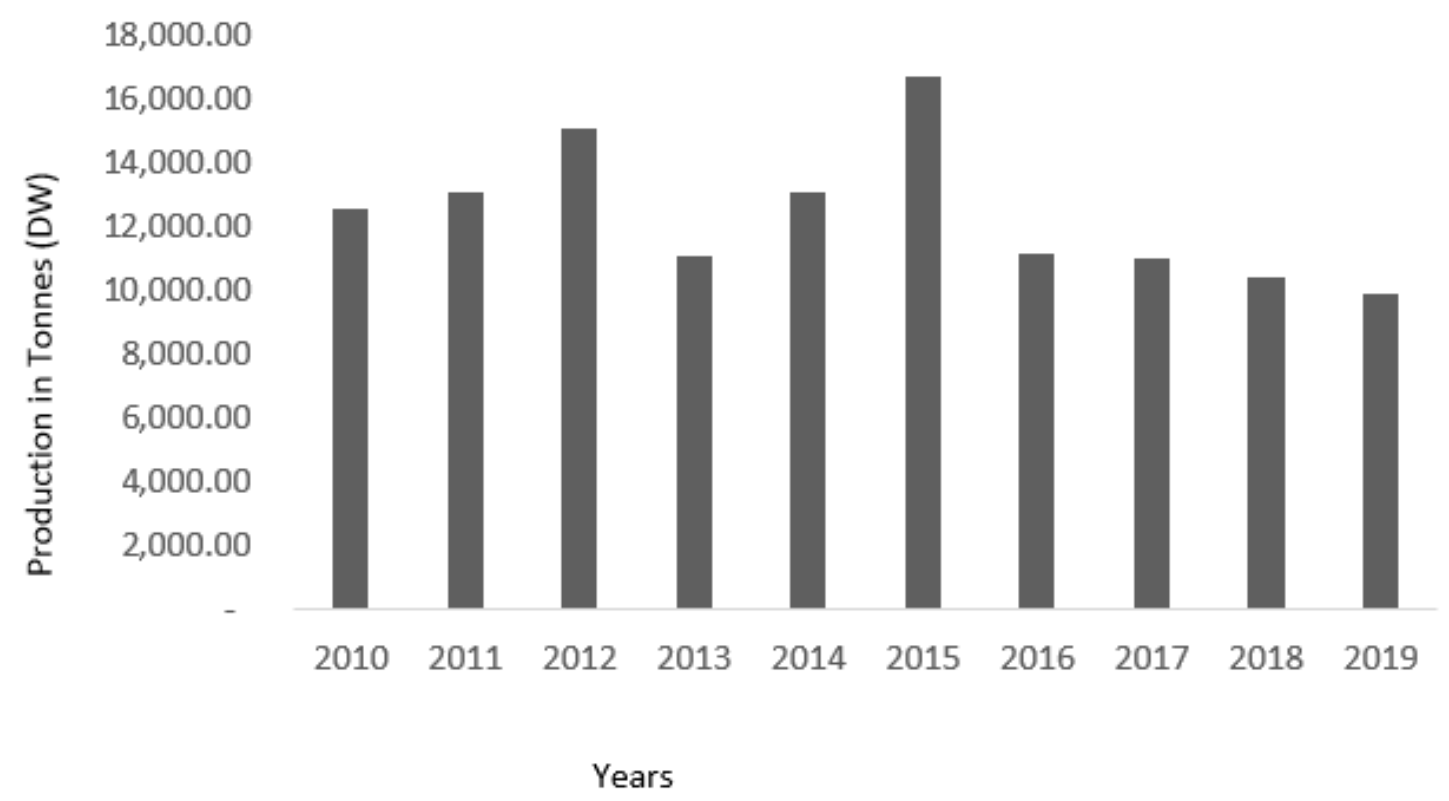

Figure 4. Annual seaweed production in Zanzibar from 2010 to 2019 in tonnes (dry weight)

\subsubsection{Climate Change Risks Affecting Seaweed as Perceived by the Farmers}

Seaweed farmers are in agreement with variability of climate around them. Farmers were asked whether rainfall, temperature and wind had increased, decreased or stay the same for the last 2 decades. The results in Table 3 show that $77.5 \%$ of the respondents across the sites perceived increased in temperature over the years. It is interesting to note the responses for the wind and rainfall are not overwhelmingly based on one response. This is probably due to the nature of these parameters. In Zanzibar, rainfall tend to have periods of highs and lows and thus it is very difficult for the individual farmers to give opinion. Studies show that the perceptions of the farmers on changing rainfall normally influenced by recent extreme events. If they experienced high rainfall recently they will perceived increased but if they experience extreme low rainfall they will perceived decreased. The results in Table 3 show that $50 \%$ of the respondents have perceived increase in rainfall while 30.6 have perceived decrease in rainfall. It is also interesting to note that $19.4 \%$ believed that rainfall amount received remain the same throughout.

Table 3. Climate parameters that have changed over the years

\begin{tabular}{cccc}
\hline Parameters & Increase & Decreased & Stayed the same \\
\hline Temperature & $77.5 \%$ & $12.7 \%$ & $9.8 \%$ \\
Rainfall & $38.1 \%$ & $48.5 \%$ & $13.4 \%$ \\
Wind & $50.0 \%$ & $30.6 \%$ & $19.4 \%$ \\
\hline
\end{tabular}

As seasons play major role in farming seaweed, respondents were asked to compare various seasons that in fact influence the growth, stability and production of the seaweed. About summer locally known as kiangazi majority of the respondents $(83.8 \%$ ) have perceived increase warming condition in this season (Table 4). While with regards to winter locally known as mchoo or pupwe $45 \% .4 \%$ believed that pupwe has become warmer than before. The 
results also showed that $36.1 \%$ and $18.6 \%$ have perceived that the winter season remain the same and has become colder than before respectively (Table 4). These two seasons are very important for the production of the seaweed farming. Colder condition favour high yield and good quality weed while warmer condition reduce production and affect the quality of the seaweed. Rainfall season are also important in determining the production of the quality seaweed. Heavy rainfall impact seaweed both at the farm and during drying the seaweed. For example, respondents across the sites asked for the assistance to acquire shade that will help them to store and dry seaweed during the rain seasons. Lack of drying places and store due to small size of their houses forced them to delay harvest. This delay of harvest may affect seaweed as it could disintegrate into pieces. The results in Table 4 show that majority of the respondents across the sites (62.5\%) perceived more rainfall during long rain season $/$ masika and $53.5 \%$ perceived lesser rain during short rainfall season. With regards to wind seasons the results show that $62.6 \%$ of the respondents believed that southerly wind (kusi) has become stronger than before. While $64.6 \%$ and $40.4 \%$ of the respondents have perceived stronger and weaker northerly wind respectively (Table 4). It is important to note that winter season is more favoured for the growth of seaweed. Nevertheless, this season is accompanied by the southerly wind (kusi) which perceived to stronger than before. Stronger wind would affect seaweed blocks stability and washed away the seaweed. This would impact the production. The findings highlight the act that although the winter season is good for the growth of the seaweed but the weed could be affected by the increasing severity of the southerly wind, which normally blow during this season.

Table 4. Comparisons of the seasons, which influence the growth of seaweed

\begin{tabular}{llll}
\hline Temperature & Warmer & Same & Colder \\
\hline Daily temperature & $74.7 \%$ & $18.2 \%$ & $7.1 \%$ \\
Summer/Kiangazi & $83.8 \%$ & $11.4 \%$ & $4.8 \%$ \\
Winter/Pupwe/Mchoo & $45.4 \%$ & $36.1 \%$ & $18.6 \%$ \\
Rainfall & More rain & Same & Less rain \\
Long rain season/Masika & $62.5 \%$ & $9.6 \%$ & $27.9 \%$ \\
Short rain season/Vuli & $21.2 \%$ & $25.3 \%$ & $53.5 \%$ \\
Wind & Stronger & Same & Weaker \\
Southerly wind (Kusi) & $62.6 \%$ & $14.1 \%$ & $23.2 \%$ \\
Northerly wind (kaskazi) & $34.6 \%$ & $25.0 \%$ & $40.4 \%$ \\
\hline
\end{tabular}

The results suggest that there is a diversity in term of perceptions on changing climate and oceanic parameters. However, majority of the seaweed farmers interviewed have perceived variability in rainfall, temperature and winds. They also perceived abnormality in the seasons and oceanic parameters such a warming of seawater, increasing salinity and increasing the intensity of salinity. Seaweed farmers across the target project sites believed that changing and local variations in climate and oceanic parameters had negative impact on the growth, yield and quality of the seaweed produced. About $57.4 \%$ of the respondents believe that climate change and its variability affect the ability of the seaweed to survive (Table 5). While $35.1 \%$ believeth that, climate change had moderate impact on the ability of the seaweed to survive (Table 5). The results also show that $53.1 \%$ and $39.6 \%$ of the respondents believed that changing in climate and oceanic parameters had high and moderate impact respectively. With regards, to crop yield the results in Table 5 show that $48.2 \%$ and $38.8 \%$ of the respondents perceived high and moderate impact of climate change on yield of the seaweed. The results also show that majority of the respondents believed that increasing frequency of storms especially within the two main wind seasons deplete the seaweed blocks and seaweed washed away. While exposure of the weed lead to increasing warming which in turn affects the seaweed farms. 
Table 5. The impact of climate change and variability on seaweed farming

\begin{tabular}{lllll}
\hline $\begin{array}{l}\text { Impact of climate change and variability on } \\
\text { seaweed }\end{array}$ & $\begin{array}{l}\text { High } \\
\text { impact }\end{array}$ & $\begin{array}{l}\text { Moderate } \\
\text { impact }\end{array}$ & $\begin{array}{l}\text { Low } \\
\text { impact }\end{array}$ & $\begin{array}{l}\text { No } \\
\text { impact }\end{array}$ \\
\hline Ability of weed to survive & $57.4 \%$ & $35.1 \%$ & $4.3 \%$ & $3.2 \%$ \\
Production/quality and quantity & $53.1 \%$ & $39.6 \%$ & $7.3 \%$ & $.0 \%$ \\
crop yield & $48.2 \%$ & $38.8 \%$ & $4.7 \%$ & $8.2 \%$ \\
Weed plots depletion and washed away & $35.4 \%$ & $38.0 \%$ & $13.9 \%$ & $12.7 \%$ \\
Seaweed exposure to the sun and desiccation & $44.3 \%$ & $36.4 \%$ & $13.6 \%$ & $5.7 \%$ \\
\hline
\end{tabular}

The fact that the impact of climate change and its variability are inevitable respondents were asked to identify strategies that they used to adapt and cope with the observed changing in weather and ocean parameters. The findings show that farmers employed various ways to cope and adapt to changes but majority of the respondents did nothing to cope and adapt to climate change and diseases and adapting to wind storm. Do nothing option means they did nothing to cope with changes. Studies show that did nothing normally associated with lack of capacity to adapt, limited awareness to the risks (climate change risks) and the perception that climate change brought by God and He alone could reduce the difficulties. Other options that are employed to cope and adapt to climate change include move to another place, replaced the destroyed seaweed, stop farming and harvest mature seaweed. With regards to the adaptation to stronger wind storms the results show that apart from did nothing adaptation options, stop seaweed farming when the storm become extreme was used. Other options employed include make sure pegs and ropes are tight and strong to increase stability of the blocks against stronger winds, and harvest matured seaweed before they are washed away by the stronger winds. With increasing warming conditions and diseases, one would expect majority of the farmers had adopted the deep-sea water method for seaweed farming. This method known for its capacity to mitigate the impact of warming and diseases. However, the findings show that no one is currently farm using this method to mitigate the impact of warming and diseases. The findings in the section 4.3 revealed that someof them had adopted this technique before but discontinued from using it for various reasons.

\subsection{Adaptation Using Deeper Seawater Seaweed Farming}

The findings in the above section highlighted the fact that majority of the respondents did nothing to cope and adapt with the observed variability and changes in climate and ocean. The results of group discussion revealed that majority of the seaweed farmers in the groups participated in this study have heard about the deep seawater seaweed farming method as option to cope with diseases and increasing warming at the intertidal zones from various sources. NGOs such as ZaSCI, MZF and others were mentioned by the farmers as their sources of information regarding this adaptive method for seaweed farming. Respondents were asked whether they tried it before. The findings revealed that $50 \%$ of the respondents have tried it before and $50 \%$ did not try this adaptation option to climate change and increasing incidence of diseases. However, when the data disaggregate gender wise, the results in Table 6 show that more male have first adopted this technique compared to female. Majority of the female farmers did not try the option; this is probably due to the fact that, the technique needs swimming and sea safety skills and access to fishing vessels to transport equipment's during planting and seaweed during harvest. These attributes favours more male compared to female.

Table 6. Early Adopters for the deeper water seaweed farming

\begin{tabular}{lll}
\hline Gender & Adopted before & Never adopted \\
\hline Male & $77.8 \%$ & $22.2 \%$ \\
Female & $43.6 \%$ & $56.4 \%$ \\
Total & $\mathbf{5 0 . 0 \%}$ & $\mathbf{5 0 . 0 \%}$ \\
\hline
\end{tabular}

One would argue that why $50 \%$ of the respondents who first adopted the technique are no longer using it while the impact of increasing warming and diseases is still exist. Studies show that individual tend to discontinue from previously adopted technique or technology if it did not reach the desired expectation. The results of this study revealed that Flower group have tried this option and the resultant yield and quality of seaweed was very high. 
However, they discontinue from using this technique because the seaweed harvested affected by rainfall during drying process due to the lack of drying facilities which can be used during both sunny and rain days. In fact, the problem was not the technique as it performed well in term of harvest and quality of seaweed, but it was the lack of drying facilities, that could protect seaweed from rainfall during drying process. Furthermore, limited or no capacity to swim amongst female seaweed farmers who are majority made them overdependence to male. The male over dependency created complication in the implementation of the deeper water seaweed farming as women cannot sail the boat, cannot dive or conduct any other related deep water farming activities and thus prompted discontinuance from the technique. Women seaweed farmers are depending on men fishers to provide them with sailing services to and from their deep-water seaweed farming sites and both seaweed farmers and fishers are working on the same days making it difficult for fishers to take part in deep water farming activities.

\subsection{Barriers to Adopting the Deep Sea Water Seaweed Farming among the Female Seaweed Farmers}

The fact the proposed adaptation measure (seed seawater seaweed farming) inhibited by the ability to swim respondents were asked if they know how to swim. The results in Table 7 show that majority of male (94.4\%) know how to swim while majority of female seaweed farmers $(77.8 \%)$ did not know how to swim. The fact that the proposed deep water farming technique is carried out between 3-4 meters during high tide and $0.5-1$ meter during low tide. The respondents were also asked in which water level they could swim. The result in Table 8 show that more male seaweed farmers $(41.2 \%)$ can swim up to 9 meters while those few female seaweed farmers who were able to swim majority of them (70.5\%) could swim between 1 and 2 meters of seawaters. This height is still not enough for them to be able to perform this method effectively. The results again highlight the need to increase capacity of the women farmers to swim to facilitate the uptake of this adaptation option. This will increase the production of quality seaweed and thus building local resilience to observed and future changes in climate and ocean.

Table 7. Ability to swim

\begin{tabular}{lll}
\hline Gender & Know how to swim & Do not know how to swim \\
\hline Male & $94.4 \%$ & $5.6 \%$ \\
Female & $22.2 \%$ & $77.8 \%$ \\
Total & $\mathbf{3 4 . 3 \%}$ & $\mathbf{6 5 . 7 \%}$ \\
\hline
\end{tabular}

Table 8. Sea water levels in which they can swim

\begin{tabular}{llllllllll}
\hline Gender & $\mathbf{1}$ meter & $\mathbf{2}$ meter & $\mathbf{3}$ meter & $\mathbf{4}$ meter & $\mathbf{5}$ meter & $\mathbf{6}$ meter & $\mathbf{7}$ meter & $\mathbf{8}$ meter & $\mathbf{9}$ meter \\
\hline Male & $.0 \%$ & $11.8 \%$ & $17.6 \%$ & $11.8 \%$ & $.0 \%$ & $5.9 \%$ & $11.8 \%$ & $.0 \%$ & $41.2 \%$ \\
Female & $35.2 \%$ & $35.3 \%$ & $5.9 \%$ & $5.9 \%$ & $5.9 \%$ & $5.9 \%$ & $5.9 \%$ & $.0 \%$ & $.0 \%$ \\
Total & $\mathbf{1 7 . 6 \%}$ & $\mathbf{2 3 . 5} \%$ & $\mathbf{1 1 . 8} \%$ & $\mathbf{8 . 8} \%$ & $\mathbf{2 . 9} \%$ & $\mathbf{5 . 9} \%$ & $\mathbf{8 . 8 \%}$ & $\mathbf{. 0 \%}$ & $\mathbf{2 0 . 6 \%}$ \\
\hline
\end{tabular}

The study highlight the fact that majority of female farmers are regardless of their age are un able to swim for them to be able to adopt this method. In both 2011, MV Spice Islander I, and 2012 MV Skargit disasters in Zanzibar, majority of the causalities were female; this is probably due to their limited capacity to swim. Study by Alim (2009) in Bangladesh show that lack of potentially lifesaving skills such as swimming can also increase women's vulnerability to floods. Schmuck (2002) estimated that $90 \%$ of the victims of the 1991 cyclone disasters were women and children in Bangladesh. This was attributable to the lack of swimming capacity among women.

Although majority of the female farmers interviewed were willing to learn swimming and sea safety skills so that they could engaged in the deep seawater seaweed farming method. However, engaging women in swimming and sea safety skills training could face barriers that need to be overcome. Respondents were asked to agree or disagree statement related to cultural and personal barriers that could affect their participation in swimming trainings. As swimming associated with special gears which can been seen as improper culturally, $38.8 \%$ of the respondents agree with the statement that swimming is associated with un-proper gears (Table 9). While $41.8 \%$ disagree with the stamen, means there no problem for them to put on swimming gears. The results also show that $19.4 \%$ of the respondents were undecided. It is also important to note that $39 \%$ of the respondents do not see the importance of learning swimming skills while $50.8 \%$ they would keen learning these skills. The results also show that $48.4 \%$ of the respondents believed that they would need permission from their husband to participate in these training while 
$48.4 \%$ of the respondents might not need permission from husband (Table 9). Interestingly, while the project intend to initiate swimming trainings $53.3 \%$ of the seaweed farmers scared high water while $38.3 \%$ were not scared of high water. About $8.4 \%$ of the respondents were not sure if they fear the high water or not (Table 9).

Table 9. Likely barriers for up taking swimming and sea safety training

\begin{tabular}{llll}
\hline Barriers & Agree & Undecided & Disagree \\
\hline Un proper gears & $38.8 \%$ & $19.4 \%$ & $41.8 \%$ \\
Not seeing the importance of knowing to swim & $39.0 \%$ & $10.2 \%$ & $50.8 \%$ \\
Permission from husband & $48.4 \%$ & $3.1 \%$ & $48.4 \%$ \\
Self-fear of high water & $53.3 \%$ & $8.4 \%$ & $38.3 \%$ \\
\hline
\end{tabular}

The findings underscore the fact that there are both cultural and personal levels barriers that are likely to constrain female seaweed famers from participating in swimming and sea safety skills training. Another set of barriers could be in the form over dependency of female farmers to their male counterpart in the entire circle of seaweed farming. For example, for the deep-water farming to be effective there should be an access to fishing vessels to assist transport input to the sites and seaweed after being-harvested. The study show that majority of the female had limited access to fishing vessels and most of them could not drive the vessels and thus depend on the male for these. The findings tallies with findings in other parts of the world. For example in Bangladesh, religious and cultural barriers and family protection probably reduced their chances to learn how to swim (Mehta, 2007; Dasgupta et al., 2010). A study by Mehta, (2007) and Dasgupta et al., (2010) in Bangladesh revealed that clothes that women wear could restrict their mobility and thus failed to escape quickly during the emergency. Similarly, it has been argued that, some culturally, gender based roles assigned to women within the societies, such as weak bargaining power, poor decision making, and limited leadership skills accelerate their vulnerability disasters situation (Aguilar, 2006; Dasgupta et al., 2010; Rahman, 2013; Ajibade et al., 2013).

\section{Conclusion}

The findings suggested that, seaweed farming is mainly practiced by female farmers and more than half of the seaweed farmers owned between 1 and 2 seaweed blocks. Despite the fact male farmers are increasing in number particularly in Pemba but female are still dominating the seaweed sector. However, the findings suggest that male/husbands and members of households play major part in seaweed activities particularly during harvesting and transportation of the harvest onshore. With limited ownership of fishing vessels amongst female, male play major part in transporting the harvested seaweed onshore for drying. The study also revealed that there is heavy domination of seaweed companies in the entire process of seaweed production from seaweed input to price of the seaweed. The findings also revealed that despite the fact that some of the seaweed farmers perceived an increase in seaweed production at the personal level, majority believed that seaweed production has decreased over time. Those who perceived decrease in the seaweed production believed that the decrease caused by increasing incidences of seaweed diseases, increasing temperature, salinity increase, increasing frequency of wind storm, lack of seaweed inputs and low price. For them low price demoralize seaweed farmers and thus reduce efforts and consequently decrease the production. Studies also revealed the impact of diseases and increasing warming conditions to the quality and yield of the seaweed, and thus reduce the production good quality seaweed.

With increasing warming condition, increasing incidence of diseases and over utilization of the intertidal zones deeper seawater seaweed farming is considered as noble option to cope and adapt to these stressors. The findings suggested that majority of the respondents are aware with existence of this method of farming seaweed. The findings also suggested that $50 \%$ of the respondents adopted the method before but they are no longer used this method for various reasons. However, majority of the male farmers have adopted the method previously compared with female seaweed farmers. Limited access to information, limited ownership and access to fishing vessels and limited capacity to swim probably hold them back from adopting this technique. Swimming is very important ingredient for this method and the results showed that majority of the female seaweed farmers are not able to swim and they lack knowledge related to sea safety. The results also revealed that majority of the female farmers are willing to learn how to swim but this could only be achieved by overcoming various personal and cultural barriers. 


\section{Acknowledgement}

This article is a result of the implementation of the project titled Building Resilience of Seaweed Farmers in Zanzibar, funded by The Global Seaweed Star of the United Kingdom. The project implemented by Milele Zanzibar Foudation (MZFZ) and The Panje Project (TPP).

\section{References}

Adger, W. N. et al. (2007). Assessment of adaptation practices, options, constraints and capacity. In Parry M. L., Canziani O. F., Palutikof J. P., van der Linden P. J., \& Hanson C. E. (Eds.), Climate change 2007: impacts, adaptation and vulnerability contribution of working group II to the fourth assessment report of the Intergovernmental Panel on Climate Change (pp. 717-743). Cambridge: Cambridge University Press.

Adger, W. N., Dessai, S., Goulden, M., Hulme, M., Lorenzoni, I., Nelson, D. R., ... Wreford, A. (2009). Are there social limits to adaptation to climate change? Climatic change, 93(3), 335-354.

Aguilar, L. (2006). Climate change and disaster mitigation: Gender makes the difference. World conservation Union (IUCN). Retrieved from www.generoyambiente.org/admin/admin_biblioteca/documentos/Climate.pdf

Ajibade, I., McBean, G., \& Bezner-Kerr, R. (2013). Urban flooding in Lagos, Nigeria: Patterns of vulnerability and resilience among women. Global Environmental Change, 23(6), 1714-1725.

Alim, M. (2009). Changes in villagers' knowledge, perceptions, and attitudes concerning gender roles and relations in Bangladesh. Development in Practice, 19(3), 300-310.

Dasgupta, S., Ismail, S., \& Sarathi, D. P. (Eds.). (2010). Women's encounter with disaster. Frontpage Publications Ltd, India.

Drowning risk assessment - Zanzibar study report, 2018. Prepared by Ipsos Limited Tanzania and The Panje Project, Submitted to Royal National Lifeboat Institute (RNLI) of the United Kingdom.

Eklund, S., \& Petterson, P. (1992). Mwani is money. The development of seaweed farming on Zanzibar and its socio economic effects in the village of Paje. Report from a minor field study. Working paper 24. Development studies unit, department of social anthropology, Stockholm University, Sweden. Retrieved from http://41.215.122.106/dspace/bitstream/0/2788/1/MWANI\%20IS\%20MONEY.pdf

Hassan, I. H., \& Othman, W. J. (2019). Seaweed (Mwani) farming as an adaptation strategy to impacts of climate change and variability in Zanzibar. In Climate Change and Coastal Resources in Tanzania (pp. 53-68). Springer, Cham.

IPCC. (2014). Climate Change 2014: Synthesis Report. Contribution of Working Groups I, II and III to the Fifth Assessment Report of the Intergovernmental Panel on Climate Change [Core Writing Team, R.K. Pachauri and L.A. Meyer (eds.)]. IPCC, Geneva, Switzerland, $151 \mathrm{pp}$.

Islam, M. M., Sallu, S., Hubacek, K., \& Paavola, J. (2014). Limits and barriers to adaptation to climate variability and change in Bangladeshi coastal fishing communities. Marine Policy, 43, 208-216.

Makame, M. O. (2013). Vulnerability and adaptation of Zanzibar east coast communities to climate variability and change and other interacting stressors. Doctoral dissertation, Rhodes University.

Masud, M. M., Azam, M. N., Mohiuddin, M., Banna, H., Akhtar, R., Alam, A. F., \& Begum, H. (2017). Adaptation barriers and strategies towards climate change: Challenges in the agricultural sector. Journal of cleaner production, 156, 698-706.

Mehta, M. (2007). Gender matters: Lessons for disaster risk reduction in South Asia, ICIMOD, Kathmandu, Nepal. Retrieved from www.gdnonline.org/resource/Gender\&disaster-preparednessICIMOD.pdf

Moser, S. C., \& Ekstrom, J. A. (2010). A framework to diagnose barriers to climate change adaptation. Proceedings of the national academy of sciences, 107(51), 22026-22031.

Msuya, F. E. (2011). Environmental changes and their impact on seaweed farming in Tanzania. World Aquaculture, $42(4), 34$.

Msuya, F. E. (2012). A study of working conditions in the Zanzibar seaweed farming industry.

Msuya, F. E. (2020). Seaweed resources of Tanzania: status, potential species, challenges and development potentials. Botanica Marina, 63(4), 371-380. https://doi.org/10.1515/bot-2019-0056

Msuya, F. E., \& Hurtado, A. Q. (2017). The role of women in seaweed aquaculture in the Western Indian Ocean 
and South-East Asia. European Journal of Phycology, 52(4), 482-494.

Msuya, F. E., Buriyo, A., Omar, I., Pascal, B., Narrain, K., Ravina, J. J., ... Wakibia, J. G. (2014). Cultivation and utilisation of red seaweeds in the Western Indian Ocean (WIO) Region. Journal of Applied Phycology, 26(2), 699-705.

Ndobe, S., Yasir, I., Salanggon, A. I. M., Wahyudi, D., Adel, Y. S., \& Moore, A. M. (2020). Eucheumatoid seaweed farming under global change-Tomini Bay seaweed trial indicates Eucheuma denticulatum (spinosum) could contribute to climate adaptation. Aquaculture, Aquarium, Conservation \& Legislation, 13(5), 2452-2467.

Pandey, R., Kumar, P., Archie, K. M., Gupta, A. K., Joshi, P. K., Valente, D., \& Petrosillo, I. (2018). Climate change adaptation in the western-Himalayas: Household level perspectives on impacts and barriers. Ecological Indicators, 84, 27-37. https://doi.org/10.1016/j.ecolind.2017.08.021

Rahman, M. S. (2013). Climate change, disaster and gender vulnerability: A study on two divisions of Bangladesh. American Journal of Human Ecology, 2(2), 72-82. https://doi.org/10.11634/216796221504315

Regmi, B. R., \& Bhandari, D. (2013). Climate change adaptation in Nepal: Exploring ways to overcome the barriers. Journal of Forest and Livelihood, 11(1), 43-61.

Richmond, M. D. (Ed.). (2010). A field Guide to the seashore of eastern Africa and the western Indian Ocean Islands (3rd ed.). Sida/WIOMSA, Stockholm/Zanzibar.

Schmuck, H. (2002). Empowering women in Bangladesh. Retrieved from http://www.reliefweb.int

Shackleton, S., Ziervogel, G., Sallu, S., Gill, T., \& Tschakert, P. (2015). Why is socially - just climate change adaptation in sub - Saharan Africa so challenging? A review of barriers identified from empirical cases. Wiley Interdisciplinary Reviews: Climate Change, 6(3), 321-344. https://doi.org/10.1002/wcc.335

SMZ. (2016). Zanzibar Household Budget Survey 2014/15. Revolutionary Government of Zanzibar, Zanzibar.

TMA. (2019). Statement on the Status of Tanzania Climate in 2019. TMA, Tanzania.

Wallevik, H. B., \& Jiddawi, N. (1999). Impacts of tourism on the activities of the women of the southeast coast of Unguja, Zanzibar. Proceeding of the 20th conference on advances in marine science in Tanzania, 939-550.

\section{Copyrights}

Copyright for this article is retained by the author(s), with first publication rights granted to the journal.

This is an open-access article distributed under the terms and conditions of the Creative Commons Attribution license (http://creativecommons.org/licenses/by/4.0/). 